\title{
MICHEL FOUCAULT Y EL PROBLEMA DEL GÉNERO
}

\author{
Ángel Pelayo González-Torre y Oscar Moro Abadía \\ Universidad de Cantabria
}

\begin{abstract}
"Sueño con el intelectual destructor de evidencias y de universalismos, el que señala e indica en las inercias y en las sujeciones del presente los puntos débiles, las aperturas, las líneas de fuerza, el que se desplaza incesantemente y no sabe a ciencia cierta dónde estará ni que pensará mañana, pues tiene centrada toda su atención en el presente."
\end{abstract}

Michel Foucault, $1977^{1}$

\section{Introducción}

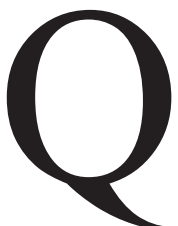

uizá Michel Foucault (1926-1984) fue la mejor encarnación de su sueño. Movido por la actualidad, eso que Nietzsche llamaba lo intempestivo, Foucault pertenece a ese tipo de pensadores que más que edificar, cavan. Como un arqueólogo excava sobre el suelo de nuestro pensamiento, sacude su elemento más familiar, accede a los cimientos de nuestro paisaje. Desde su actualidad, Foucault despliega su mirada genealógica hacia aquellos elementos que pensábamos universales, evidentes, naturales.

Como el propio filósofo cuenta, allá por la década de los setenta esa mirada se dirigió hacia la sexualidad: "Quería detenerme delante de esta noción, tan cotidiana, de sexualidad: tomar perspectiva con respecto a ella, experimentar su evidencia familiar, analizar el contexto teórico y práctico en el que apareció y al que todavía está asociada." "Sexo" y "sexualidad", ¿Qué significan esos conceptos tan intensos, sobrecargados, candentes? Para tratar de dar respuesta a ésta y a otras cuestiones que recorren su obra

\footnotetext{
${ }^{1}$ Foucault, M.; "No al sexo rey. Entrevista por Bernard Henry-Levy", en Michel Foucault: Un diálogo sobre el poder y otras conversaciones, Madrid, Alianza Editorial, 1988 (original: 1977), pp. 163-164.

${ }^{2}$ Foucault, M.; "Preface to the History of Sexuality", en Michel Foucault. Dits et écrits II, 1976-1988, Paris, Gallimard, 2001 (original 1984), p. 1397
} 
(poder, saber, formas de subjetivación), Foucault trabajó durante los últimos diez años de su vida. Fruto de ese esfuerzo, dejó algunos libros (los tres volúmenes de la Historia de la sexualidad) y una serie de materiales dispersos ${ }^{3}$ que levantaron una gran polvareda en el paisaje de la sexualidad contemporánea. Basta con repasar la abundante bibliografía al respecto para darse cuenta del impacto que el filósofo ejerció, y sigue ejerciendo, sobre ese cajón de sastre que los anglosajones denominan Gender Studies. Ya sea para canonizarle o para criticarle con dureza, lo cierto es que alguna de las principales corrientes que han recorrido el feminismo, la Queer Theory o el movimiento de gays y lesbianas durante los últimos años han convertido a Foucault en una referencia fundamental.

El bullicio ha sido tal que creemos ha llegado la hora del balance. Consideramos que existen dos posibilidades para llevar a cabo esta tarea: Proceder a un análisis temático que permita comprender la influencia del filósofo francés sobre cada uno de los campos que componen los Gender Studies, o examinar la referencia a la que remiten dichos análisis, es decir, volver sobre el trabajo de Foucault. La primera de estas dos opciones ha rastreado el impacto de la filosofía foucaultiana sobre la sexualidad contemporánea tratando de responder a una serie de preguntas fundamentales: ¿Por qué un filósofo cuyo "compromiso con el feminismo fue mínimo" influyó tanto sobre pensadoras feministas de la talla de Judith Butler, Jana Sawicki o Susan Bordo? ¿Por qué Foucault "se convirtió en el icono de la Queer Theory"s? ¿Por qué un pensador tan reticente a definir su sexualidad acabó por convertirse en un santo gay ${ }^{6}$ ? Esta ligne de recherche ha aportado excelentes resultados (particularmente en el caso del feminismo) ${ }^{7}$ y poco podríamos aportar nosotros al respecto.

\footnotetext{
${ }^{3}$ Recopilados en su mayor parte por Daniel Defert y de François Ewald: Foucault, M.; Dits et écrits, Paris, Gallimard, 2001.

${ }^{4}$ Sope, K.; "Productive contradictions" en C. Ramazanoglu (ed.); Up Against Foucault. Explorations of some tensions between Foucault and feminism, London and New York, Routledge, 1993, p. 29.

${ }^{5}$ Macey, D.; The Penguin Dictionary of Critical Theory, London, Penguin Books, 2001, p. 135 .

${ }^{6}$ HalPerlin, D.; Saint Foucault. Towards a Gay Hagiography, Oxford, Oxford University Press, 1995.

${ }^{7}$ Es obligado mencionar al heterogéneo grupo de pensadoras feministas (Frazer, Butler, Ramazanoglu, Sawicki, Bell, etc.) que han trabajado sobre Michel Foucault, mostrando tanto sus contradicciones (especialmente su incapacidad para escapar de un horizonte de pensamiento androcéntrico) como las posibilidades de aplicación de su filosofía a estudios concretos (como hizo Susan Bordo en el caso de la anorexia nerviosa). Dado que es imposible resumir tan magna aportación, nos limitamos a sugerir al lector una bibliografía básica al respecto:
} 
Quizá por ello hemos apostado por la segunda posibilidad: Retomar la referencia original y proponer un trabajo de síntesis que permita presentar al lector los elementos claves del análisis foucaultiano sobre una sexualidad definida como una experiencia compleja donde se anudan un campo de conocimiento, un conjunto de reglas y un modo de relación consigo mismo. Este será, por tanto, el objetivo de este artículo.

\section{2. ¿Por qué la sexualidad?}

Nuestra primera tarea será determinar las causas que llevaron a Foucault a interesarse por la sexualidad. Tal y como han señalado sus biógrafos, ${ }^{8}$ para comprender la dimensión de su trabajo será necesario considerar tanto su sexualidad como su afición por ciertas prácticas sexuales (el sadomasoquismo). Sin embargo, es necesario escapar de la disyuntiva que plantean quienes consideran que la filosofía de Foucault debe ser analizada sin hacer referencia a su biografía y quienes, como escribe Eribon a propósito de la biografía de Miller, pretenden "explicar toda la obra de Foucault a partir del sadomasoquismo". ${ }^{9}$ Frente a dicha dicotomía reductora, preferimos partir de la idea heideggeriana que supone que la filosofía no nace del pensamiento, sino que brota del estado de ánimo, entendido como un vínculo entre el propio pensamiento y la vida. En el origen de la filosofía está la angustia, la felicidad, la duda. En este sentido, el interés de Foucault por la sexualidad parece derivarse más bien de su comprensión de la misma como un espacio privilegiado donde se anudan muchas de sus preocupaciones vitales y filosóficas.

En primer lugar, la sexualidad es el lugar donde algunas de sus inquietudes personales se plantean con más claridad. Dos de esas preocupaciones destacan sobre el resto: la identidad y el placer. Para Foucault, el problema de la identidad fue siempre fundamental: "Más de uno, como yo sin duda, escribe para perder el rostro. No me pregunten quien soy y no me pidan que permanezca invariable." ${ }^{10}$ La interpretación de la identidad como forma de

Diamond, I. \& Quinby. L. (eds.); Feminism and Foucault: Reflections on Resistance, Boston, Northeastern University Press, 1988. ; SAwICKI, J.; Disciplining Foucault. Feminism, power and the body, London \& New York, Routledge, 1991. Ramazanoglu, C. (ed.); Up Against Foucault. Explorations of some tensions between Foucault and feminism, London and New York, Routledge, 1993. Bell, V.; Interrogating incest. Feminism, Foucault and the Law, London and New York, Routledge, 1993.; Hexman, S. J. (ed.); Feminist interpretations of Michel Foucault, Pennsylvania, The Pennsylvania State University Press, 1996.

${ }^{8}$ Eribon, D.; Michel Foucault (1926-1984), Paris, Flammarion, 1989. Macey, D.; The lives of Michel Foucault, New York, Vintage Books, 1993. Miller, J.; The passion of Michel Foucault, Glasgow, Harper Collins, 1993.

${ }^{9}$ Eribon, D.; op. cit. 1989 , p. 40.

${ }^{10}$ Foucault, M.; La arqueología del saber, Madrid, S.XXI, 1990 (original 1969), p. 29. 
opresión está sin duda relacionada con el rechazo que llevaba a Foucault a enfurecerse cuando alguien le definía como estructuralista, o a exaltar las delicias del exilio, "ese placer de estar de sobra, tan indiferente como una cosa." Lo esencial, sin embargo, es la liaison que Foucault establece entre la cuestión de la identidad y la sexualidad tal y como esta es definida en la sociedad contemporánea. En dicha sociedad, que en otras ocasiones denomina disciplinaria, "se exige una correspondencia rigurosa entre el sexo anatómico, el sexo jurídico, el sexo social: esos sexos tienen que coincidir y nos colocan en una de las dos columnas de la sociedad."12 En la civilización moderna se da a cada uno su identidad sexual primera, profunda y determinante. A Foucault esas exigencias debieron resultarle insoportables. Frente a la búsqueda de la identidad, prefirió siempre lo que Deleuze llamaba despersonalización: "El nombre propio no designa un individuo: al contrario, un individuo sólo adquiere su verdadero nombre propio cuando se abre a las multiplicidades que lo atraviesan totalmente, tras el más severo ejercicio de despersonalización.”13

La sexualidad es también el lugar donde se plantea la cuestión del placer. Como veremos más adelante, para Foucault la búsqueda del placer fue algo prioritario a lo largo de su vida: "Tengo dificultades para experimentar la experiencia del placer. El placer me parece una conducta muy difícil [...] Y tengo que reconocer que es mi sueño. Quisiera y espero morir de una sobredosis de placer del tipo que sea, porque [...] he tenido siempre la impresión de no experimentar el verdadero placer, el placer completo y total; y este placer, para mí, está ligado a la muerte" 14 . Sin embargo, esa búsqueda ${ }^{15}$ chocó con el erotismo disciplinario propio de nuestra sociedad. Según Foucault, desde hace dos siglos Occidente ha establecido una relación entre poder, verdad y placer (la scientia sexualis) donde lo que importa es menos el placer que el deseo y donde el goce sexual está relacionado con la enunciación de la verdad. En definitiva, nuestra sociedad ha formulado una sexualidad de la que Foucault propondrá liberarse a través de una multiplicación de los placeres: "Hay que inventar con el cuerpo, con sus elementos, sus su-

\footnotetext{
${ }^{11}$ Eribon, D.; Reflexiones sobre la cuestión gay, Barcelona, Anagrama, 2001, p. 349.

${ }^{12}$ Foucault, M.; "Il misterioso ermafrodito", en Michel Foucault. Dits et écrits II, 19761988, Paris, Gallimard, 2001 (original 1978), p. 624.

13 Deleuze, G. y Guattari, F.; Mil mesetas. Capitalismo y esquizofrenia, Valencia, Pretextos, 1988, p. 43.

${ }^{14}$ Foucault, M.; "Michel Foucault. An Interview with Stephen Riggins", en Michel Foucault. Dits et écrits II, 1976-1988, Paris, Gallimard, 2001 (original 1983), p.1352.

${ }^{15}$ Búsqueda sin duda relacionada con su afición consumo de drogas: "Ciertas drogas son verdaderamente importantes para mí, porque me permiten tener acceso a esos placeres terriblemente intensos que busco, y que no soy capaz de alcanzar sólo”, en: Idem, p. 1353.
} 
perficies, sus volúmenes, sus espesores, un erotismo no disciplinario: el del cuerpo en estado volátil y difuso, con sus encuentros al azar y sus placeres sin cálculo". ${ }^{16}$

Pero a Foucault la sexualidad no le interesa solamente por ser el teatro de algunas de sus inquietudes vitales, sino también porque en ella se anudan algunas de sus preocupaciones filosóficas fundamentales. Para Foucault la sexualidad es ante todo un campo de experiencia donde poder y saber, discursos y prácticas, poder-represión y poder-incitación, verdad y ética se constituyen en un dominio complejo. Es ese carácter topológico privilegiado lo que le lleva a convertir la pregunta por la sexualidad en un ejercicio filosófico : "Quisiera subrayar que la sexualidad no es más que un ejemplo de un problema general que persigo desde hace más de quince años y que me persigue desde hace más de quince años. Es el problema que determina casi todos mis libros: ¿Cómo, en las sociedades occidentales, la producción de discursos cargados, al menos durante un tiempo determinado, de un valor de verdad está ligada a los diferentes mecanismos e instituciones del poder"17

Por estas razones, a mediados de la década de los setenta Foucault se plantea una genealogía de la sexualidad que permita determinar por qué las sociedades europeas han tenido necesidad de lo que denomina una scientia sexualis.

\section{La genealogía de la sexualidad}

En primer lugar, Foucault plantea el carácter histórico y contingente del concepto sexualidad y de toda una serie de nociones que, debido a la familiaridad, hoy nos parecen indiscutibles ("sexo", "homosexualidad", etc.). Como escribe a propósito del libro de K. J. Dover Greek Homosexuality, ${ }^{18}$ lo importante es como su autor demuestra que "nuestra división de las conductas sexuales entre homo y heterosexualidad no era en absoluto pertinente para los Griegos y los Romanos. [...] Una persona que se acostaba con otra del mismo sexo no se sentía como homosexual"19. Foucault recurre a la historia para mostrar cómo la sexualidad es una categoría que no tiene más de tres siglos: "Los griegos y lo romanos tenían un término para designar los actos sexuales, los aphrodisia [...] Se trata en todo caso de actividades

${ }^{16}$ Foucault, M.; "Sade, sergent du sexe", en Michel Foucault. Dits et écrits I, 1954-1974, Paris, Gallimard, 2001 (original 1975), p. 1690.

${ }^{17}$ Foucault, M.; "Sexualität und Wahrheit", en Michel Foucault. Dits et écrits II, 19761988, Paris, Gallimard, 2001 (original 1977), p. 137.

${ }^{18}$ Dover, K. J. 1978. Greek Homosexuality, London, Duckworth.

${ }^{19}$ Foucault, M.; "Entretien avec Michel Foucault", en Michel Foucault. Dits et écrits II, 1976-1988, Paris, Gallimard, 2001 (original 1982), p. 1105. 
sexuales, pero en absoluto de una sexualidad." ${ }^{\prime 20}$ La sexualidad es, por tanto, una forma de experiencia específica del hombre moderno, como los aphrodisia lo fueron para los griegos, o la carne para los cristianos. De hecho, la definición de una persona sexual sólo fue posible a partir de la consolidación, hacia el siglo XVIII, de lo que Foucault denomina el dispositivo de la sexualidad: "En la cultura griega [...] era simplemente impensable que alguien fuera esencialmente homosexual en su identidad [...] No fue más que a partir del momento en el que el dispositivo de la sexualidad funcionó [cuando] la cuestión "¿Qué ser sexual es usted?" llegó a ser inevitable". ${ }^{21}$

Una vez determinado el carácter histórico/ contingente de la sexualidad, Foucault propone esbozar su genealogía en términos positivos a través del análisis de dos conceptos profundamente relacionados: el dispositivo de la sexualidad y la scientia sexualis.

Por dispositivo de la sexualidad, Foucault entiende el conjunto de prácticas, instituciones y conocimientos que hacia el siglo XVIII hicieron de la sexualidad un dominio coherente y una dimensión absolutamente fundamental del individuo. Frente a quienes proponen una configuración de la sexualidad como represión, Foucault manifiesta sus dudas: "¿Y si esto no fuera lo esencial?, ¿y si hubiera en el centro de la política del sexo" mecanismos bien diferentes? ¿y si esos mecanismos no fueran de rechazo y de ocultación, sino de incitación? ¿y si el poder no tuviera por función esencial decir no, prohibir y censurar, sino ligar en una espiral indefinida la coerción, el placer y la verdad?"22 Es decir, ¿y si la represión no fuera la característica que define la sexualidad en nuestras sociedades? No se trata de negar que no haya existido represión sobre la sexualidad, sino de insertar esa hipótesis represiva en un dispositivo más amplio que permita comprender la sexualidad como un campo estratégico donde se ligan discursos, prácticas, tácticas, estrategias, poder-represión, poder-incitación y modos de subjetivación.

El segundo concepto fundamental a la hora de comprender la genealogía de la sexualidad es el de sciencia sexualis. Para Foucault es posible hablar de dos tipos de sociedades en relación con la definición de las relaciones sexuales que puede establecerse: aquellas en las que el discurso sobre el sexo no intenta fundar una ciencia sino definir un arte (ars erotica) apoyándose sobre el placer; y aquellas otras donde dicho discurso ha adoptado una forma científica. Las sociedades donde reinó el arte erótico (p.e. Grecia

\footnotetext{
${ }^{20}$ Foucault, M.; "Interview met Michel Foucault", en Michel Foucault. Dits et écrits II, 1976-1988, Paris, Gallimard, 2001 (original 1984), p. 1480.

${ }^{21}$ Idem, pág. 1481.

${ }^{22}$ Foucault, M.; "L'Occident et la vérité du sexe”, en Michel Foucault. Dits et écrits II, 1976-1988, Paris, Gallimard, 2001 (original 1976), p. 103.
} 
antigua, Roma, etc.) investigaron en los métodos de intensificación del goce sexual, transmitieron los secretos del placer a través de la figura del maestro y extrajeron la verdad del propio placer. En ellas, el saber debía revertir sobre la práctica sexual. Por el contrario, al menos desde la Edad Media en Occidente no ha existido ars erotica sino una ciencia del sexo o "tipo de saber donde lo que se analiza no es tanto el placer como el deseo; donde el maestro no tiene por función iniciar, sino interrogar, escuchar, descifrar; donde todo ese largo proceso no tiene por objetivo un aumento del placer, sino una modificación del sujeto (que, de este modo, se encuentra perdonado o reconciliado, curado o liberado)" ${ }^{23}$

Foucault muestra la formación histórica de esta manera de organizar las relaciones entre poder, verdad y placer en el primer volumen de la historia de la sexualidad. Así, durante el siglo XIX el sexo se inscribió en dos registros distintos. Por un lado una biología de la reproducción, constituida de acuerdo con una normatividad científica y relacionada con la voluntad de saber que en Occidente implicó la institución del discurso científico. Por otro lado una medicina del sexo, donde lo que se puso en juego era más bien una voluntad de no-saber, un deseo de esquivar la verdad. En ambos casos, lo esencial es que alrededor del sexo se articuló un aparato para la producción de la verdad. Al contrario que en las sociedades del ars erotica, el sexo no será una cuestión de placer, de querer, de voluntad, sino de verdad y de falsedad. Sexo y verdad quedaron ligados para convertirse en una de las preocupaciones más constantes de las sociedades occidentales. Aunque dichas sociedades multiplicaron las instituciones y estrategias para "arrancar la verdad del sexo", lo cierto es que la principal táctica de producción de lo verdadero fue un ritual establecido desde la Edad Media: la confesión. Será hacia finales del siglo XVIII cuando la scientia sexualis se constituya como ciencia apoyándose en los rituales de la confesión y produciendo alrededor del sexo una especie de fusión, una "interferencia entre dos modalidades de producción de lo verdadero: los procedimientos de confesión y la discursividad científica." 24 De esta manera, la scientia sexualis nace del ajustamiento de los procedimientos de confesión a un discurso científico. La sexualidad aparece en el siglo XIX en el punto de convergencia de dos vectores: Una técnica (la confesión) y una discursividad (la científica).

La relación entre sexo y verdad tal y como se articula en la scientia sexualis es el objeto de la genealogía foucaultiana: “¿Por qué Occidente se ha interrogado tan continuamente sobre la verdad del sexo y ha exigido que

\footnotetext{
${ }^{23}$ Idem, pág. 104.

${ }^{24}$ Foucault, M.; Historia de la sexualidad. La voluntad de saber, Madrid, Siglo Veintiuno, 1977 (original 1976), p. 82.
} 
cada uno la formule por sí mismo? ¿Por qué ha querido con tanta obstinación que nuestra relación con nosotros mismos pase por esta verdad?"25 Bajo la epidermis de esa voluntad, Foucault descubre el fluir del poder. Un poder que toma esa sexualidad (constituida en tanto que saber) como soporte, como punto de apoyo. Un poder que no busca suprimir la sexualidad, sino asentarse sobre ella, fundirse con ella, multiplicarse a través de ella. El poder en la sociedad contemporánea no ha instaurado una edad de represión definida por un silencio que envuelve al sexo, sino que ha procedido a una multiplicación de los discursos sobre la sexualidad. Con la consolidación de una scientia sexualis, el poder se desplegó a través de un doble movimiento: instauró una determinada política del cuerpo y procedió a una definición de los individuos. Efectivamente, desde el siglo XVIII el poder ha definido una "política del cuerpo" muy concreta: "Desde los siglos XVII y XVIII el cuerpo humano ha sido a la vez utilizado, cuadriculado, encerrado, encorsetado como fuerza de trabajo. Esta política consistía en extraer de él el máximo de fuerzas utilizables para el trabajo y el máximo de tiempo utilizable para la producción." ${ }^{26}$ Esa política del cuerpo define un erotismo disciplinario del que Sade tal vez sea el mejor ejemplo ${ }^{27}$ y que es correlativa a una catalogación de los individuos que define su identidad. El poder no pretende suprimir lo que Foucault denomina sexualidades periféricas (refiriéndose a las sexualidades diferentes de la normativa, es decir de la reproductora de la fuerza del trabajo) sino que las dota de realidad construyendo identidades. El siglo XIX será el acta de nacimiento de la innumerable familia de los perversos: homosexuales, pedófilos, masoquistas, necrófilos, etc. A través de la constitución de una scientia sexualis el poder ha experimentado una mutación en la manera de actuar sobre las conductas sexuales de la gente: ha pasado de condenar actos a definir individuos. El propio Foucault explica esta metamorfosis: "En otro tiempo, las leyes prohibían un cierto número de actos, actos por otra parte tan numerosos que no se llegaban muy bien a definir. De cualquier manera, eran actos que la ley castigaba. Se condenaban formas de conducta. Ahora, lo que se está definiendo, y lo que, por consiguiente, va a fundamentarse por la intervención de la ley, del juez, del médico, son los individuos peligrosos". ${ }^{28}$

\footnotetext{
${ }^{25}$ Foucault, M.; "L'Occident et la vérité du sexe", en Michel Foucault. Dits et écrits II, 1976-1988, Paris, Gallimard, 2001 (original 1976), p. 105.

${ }^{26}$ Foucault, M.; "Sexualité et politique", en Michel Foucault. Dits et écrits I, 1954-1975, Paris, Gallimard, 2001 (original 1974), p. 1405.

27 "Una sociedad reglamentaria, anatómica, jerarquizada, con su tiempo cuidadosamente distribuido, sus espacios cuadriculados, sus obediencias y sus vigilancias," en: Foucault, M.; “Sade, sergent du sexe ", en Michel Foucault. Dits et écrits I, 1954-1975, Paris, Gallimard, 2001 (original 1975), p. 1690.

${ }^{28}$ Foucault, M.; "La loi de la pudeur", en Michel Foucault. Dits et écrits II, 1976-1988, Paris, Gallimard, 2001 (original 1979), p. 772.
} 
Al mismo tiempo, ese poder que se expande a través de una scientia sexualis define un tipo de placer distinto del propio del ars erotica: "Se ha dicho en ocasiones que Occidente no ha sido jamás capaz de inventar un placer nuevo. ¿No cuenta para nada la voluntad de hurgar, acosar, interpretar; en resumen, el "placer de analizar" en el sentido amplio del término?."29 En su ejercicio de estrecha vigilancia, el poder descubre el placer ( para nosotros triste ) de vigilar: "El placer descubierto fluye hacia el poder que lo ciñe. ${ }^{30}$ El poder se deja invadir por el placer que vigila con tanto celo, ligándose ambos en una espiral perpetua.

Por último, no quisiéramos concluir este epígrafe sin tratar de responder a la cuestión clave: ¿Por qué Foucault propone la genealogía histórica del concepto sexualidad?, ¿por qué muestra su carácter histórico y contingente?, ¿para qué una historia de la sexualidad? La respuesta está en el propio significado del proyecto genealógico: "Genealogía quiere decir que yo mismo lo analizo a partir de la cuestión presente." 31 Siempre que Foucault se acercó a la historia fue desde la relación con su presente. La historia sólo le interesa porque señala el punto de partida, la cadena que debemos romper para enfrentarnos con nuestro presente, el lugar donde las falsas identidades que se nos atribuyen encuentran sus falsas coartadas. Deleuze lo dijo con brillantez: "Foucault no se convirtió nunca en historiador. Foucault es un filósofo que ha inventado una relación con la historia completamente distinta a la de las filosofías de la historia. La historia, según Foucault, nos cerca y nos delimita, no dice lo que somos sino aquello de lo que diferimos, no establece nuestra identidad sino que la disipa en provecho de eso otro que somos [...] La historia es lo que nos separa de nosotros mismos, y lo que debemos franquear y atravesar para pensarnos a nosotros mismos" ${ }^{\text {" }} 2 \mathrm{En}$ definitiva, si Foucault afronta una genealogía histórica de la sexualidad es, como diría Bourdieu, para "volver a poner en marcha la historia" 33 y mostrar que dicha historia implica una forma concreta de entender las relaciones sexuales que podría y puede adoptar una forma diferente. ${ }^{34}$ Una forma di-

${ }^{29}$ Foucault, M.; "L’Occident et la vérité du sexe", en Michel Foucault. Dits et écrits II, 1976-1988, Paris, Gallimard, 2001 (original 1976), p. 103.

${ }^{30}$ Foucault, M.; Historia de la sexualidad. La voluntad de saber, Madrid, Siglo Veintiuno, 1976 (original 1977), p. 58.

${ }^{31}$ Foucault, M.; "El cuidado de la verdad", en Michel Foucault. Estética, ética y hermenéutica. Obras esenciales. Volumen III, Barcelona, Paidós, 1999 (original 1984), p. 376.

${ }^{32}$ Deleuze, G.; Conversaciones, Valencia, Pre-textos, 1995, pp. 154-155.

${ }^{33}$ Bourdieu, P; La dominación masculina, Barcelona, Anagrama, 1998, p. 8.

${ }^{34}$ En este punto, el proyecto de Foucault y el de Bourdieu convergen. En su trabajo sobre la dominación masculina, Bourdieu sostiene que hay que preguntarse "cuáles son los mecanismos históricos responsables de la deshistoricización y de la eternización relativas de las estructuras de la división sexual y de los principios de división correspondientes" (Idem, págs. 7-8). De 
ferente que Foucault no se atreve a proponer pero si a esbozar: la creación de los modos de vida.

\section{El verdadero sexo}

Esta es, en líneas generales, la genealogía histórica que Foucault propone de la sexualidad, un concepto tan familiar para nosotros que le creíamos universal. Sin embargo, esa es sólo la mitad del problema. En realidad, genealogía quiere decir a la vez "la filosofía de los valores, [...] la verdadera realización de la crítica, la única manera de realizar la crítica total, es decir, de hacer filosofía a "martillazos" 35 y, al mismo tiempo, significa "la expresión activa de un modo de existencia activo". ${ }^{36}$ Genealogía es, por tanto, crítica y acción, inseparables en la mixtura de lo concreto.

$\mathrm{Y}$ es que dando por sentado que el poder no sólo reprime, sino que también produce, es importante no agotarse en una posición defensiva. Foucault inaugura una línea de trabajo en la que la denuncia va acompañada de la invención de proyectos y modos de vida, de la enunciación de nuevos discursos y de la puesta en marcha de nuevas prácticas. Hay que elaborar proyectos y modos de vida originales, con libertad respecto de los condicionamientos que han determinado hasta ahora los discursos de verdad y las prácticas organizadas en torno al sexo. Foucault entiende la resistencia no sólo como un ejercicio genealógico destinado a reintegrar la sexualidad en lo histórico, sino también como un proceso de creación de nuevos modos de vida en el que, como veremos, la imaginación va a jugar un papel protagonista. Ahora bien, en este proceso resulta fundamental, como paso previo, escapar de las formas preexistentes de identificación sexual.

Esencialmente, las formas productivas de sujeción, el entramado saberpoder-verdad que se ha manejado para construir una ciencia del sexo, se concreta en la noción de verdadero $\operatorname{sexo}^{37} \mathrm{o}$ atribución al sujeto de un sexo au-

acuerdo con el sociólogo francés, "recordar que lo que, en la historia, aparece como eterno es sólo el producto de un trabajo de eternización [significa] reinsertar en la historia, y devolver, por tanto, a la acción histórica, la relación entre los sexos que la visión naturalista y esencialista les niega" (Idem, pág. 8)

${ }^{35}$ Deleuze, G.; Nietzsche y la filosofía, Barcelona, Anagrama, 1971, pág. 7.

${ }^{36}$ Idem, pág. 9.

${ }^{37}$ Es importante hacer una aclaración con respecto a este concepto. Como bien ha señalado Judith Butler, Foucault nunca afirmó que los personas no tengamos un sexo (tal y como han pretendido ciertas interpretaciones derivadas de una lectura simplista de su conocida frase: "¿Tenemos verdaderamente necesidad de un verdadero sexo?") sino que, frente a posiciones esencialistas, defendió que dicho sexo es una construcción: "Foucault propone la existencia de una ruptura histórica decisiva entre un régimen socio-político en el que el sexo existía como un atributo, una actividad, una dimensión de la vida humana y un régimen más reciente en el que el sexo se definió como una identidad [...] Por lo tanto, no es correcto declarar que nunca 
téntico que le corresponde y al que va a quedar estrechamente ligado. Dicho concepto resume el lazo fundamental que Foucault establece entre nuestra subjetividad, nuestra identidad y nuestra sexualidad. De ahí que haya que dedicar especial atención, antes de empeñarse en cualquier esfuerzo productivo, a desprenderse de la sujeción a ese verdadero sexo, estrecho y opresivo. El peso de esta estricta identificación sexual radica en que va a funcionar como un mecanismo de producción de sujetos, un mecanismo que articula formas de subjetivación (esencialmente la distinción entre hombre y mujer, pero también muchas otras clasificaciones como homosexual/ heterosexual, onanista, pederasta, zoófilo, etc.) que catalogan a las personas de forma muy estrecha, marcando y disciplinando las pautas del comportamiento y las relaciones sociales, de manera que a la postre enclaustran la personalidad, constriñen el ejercicio del placer y son un paso previo a toda una política del cuerpo. Por otro lado, esas formas de subjetivación acaban convirtiéndose en campos reconstruidos para el ejercicio del poder. Por ejemplo, la distinción homosexual/ heterosexual, que se enuncia habitualmente en un contexto homófobo, o la clasificación hombre/ mujer, que lo hace en un contexto machista, aparecen como dicotomías clasificatorias aptas para el posterior ejercicio de tramas de poder entre los sujetos. En otros casos en los que la calificación es presentada simplemente como una patología, también resulta fácilmente ligada a mecanismos de opresión.

En su intento por hacer estallar la noción de verdadero sexo, Foucault trabajó a dos niveles. Por un lado, tomando como ejemplo el hermafroditismo, criticó el argumento más débil sobre el que se apoyan los procesos de subjetivación ligados al verdadero sexo; a saber, que dichos procesos son la consecuencia natural de una división anatómica incontestable entre el macho y la hembra. Foucault aborda este problema en algunos textos publicados entre 1978 y 1980. Por otro lado, tomando como ejemplo la homosexualidad, Foucault mostró la posibilidad de subvertir la idea de un verdadero sexo a través de aquellas categorías que, creadas por la scientia sexualis y colocadas en los límites de la normalidad, ponen en entredicho las pretensiones de naturalidad de las relaciones sexuales consideradas naturales: las relaciones heterosexuales.

\section{A. Herculine, el misterioso hermafrodita}

En primer lugar, por tanto, la crítica del argumento esencialista que considera la sexualidad como la causa lógica de la incontestable división

hemos tenido un sexo", en: Butler, J. "Sexual Inversions", en Susan J. Hekman (ed.); Feminist Interpretations of Michel Foucault, Pennsylvania, The Pennsylvania State University Press, 1996, p 59. 
anatómica entre machos y hembras. El texto fundamental en este sentido es Le vrai sexe, ${ }^{38}$ donde Foucault repasa la vida de Alexina, el misterioso hermafrodita. El propio filósofo resume la historia de este hermafrodita de la segunda mitad del siglo XIX: "Educada como una muchacha pobre y respetable en un medio casi exclusivamente femenino y fuertemente religioso, Herculine Barbin, apodada en su entorno Alexina, fue reconocida finalmente como un "verdadero" muchacho; obligada a cambiar de sexo legal, después de un procedimiento judicial y de una modificación de su estado civil, fue incapaz de adaptarse a su nueva identidad y acabó suicidándose". ${ }^{39}$

Dicha historia le sirve como ejemplo para mostrar no sólo la dificultad de encajar algunos casos en los márgenes de las categorías descritas por esa estrecha scientia sexualis, sino, sobre todo, como demostración de la inexistencia misma de un verdadero sexo. La historia de la vida de Herculine es presentada como la prueba de la posibilidad de estados de sexualidad inclasificables, indeterminados en su género y por añadidura felices.

Efectivamente, mientras preexiste una anatomía más o menos clara y determinada, la esencia del esquema clasificatorio, la dicotomía entre los sexos, mantiene sus pretensiones de naturalidad. Pero Foucault bucea en el caso intermedio de una indefinición ambigua, de una realidad corporal inconcreta, que utiliza para criticar la atribución del verdadero sexo, y para poner de manifiesto el carácter contingente y potencialmente represivo de esa estricta exigencia de identificación.

El juego de saber-verdad tiene su principal baza en una jugada que consiste en hacer confesar al sujeto su afiliación a un sexo ya catalogado y del que todo está dicho. De ahí la obsesión por dar a cada uno un sexo y uno único. Entre otras cosas, esta atribución se convierte en necesaria porque no hay discurso para las personas sin verdadero sexo. Estas se mueven en un vacío en el que sus protagonistas, difíciles de encajar, son vistos con temor como fantasmas de la naturaleza, susceptibles de protagonizar, explotando sus rarezas anatómicas y sus ambigüedades afectivas, extrañas relaciones que, incatalogables, se pueden acabar considerando extravíos del libertinaje. Por eso se busca la imposición de un verdadero sexo que en ocasiones, como en el caso de Alexina, forzará la realidad de cuerpo y dislocará la intensidad del placer al imponer a una anatomía ambigua el duro juego de esa verdad.

En su indagación sobre modos de vida no codificados, Foucault se volcará interesado en la descripción de la vida de Alexina, a la que presentará

\footnotetext{
${ }^{38}$ Foucault, M; "Le vrai sexe", en Michel Foucault. Dits et écrits II, 1976-1988, Paris, Gallimard, 2001 (original 1980), pp. 934-942

${ }^{39}$ Idem, págs. 937-938.
} 
moviéndose en un mundo confortable exento de definiciones. Adolescente en un internado de señoritas, el hermafrodita ambiguo disfruta allí de las delicias que experimenta por no tener un sexo definido. Con un tono evocador, Foucault va a hacer levitar a su protagonista en los "limbos felices de una no-identidad que protegía paradójicamente la vida en estas sociedades cerradas, estrechas y cálidas" ${ }^{40}$ que eran los internados. Allí transcurren los días más felices de la vida de Alexina: "Ni mujer que amaba a las mujeres ni hombre escondido entre las mujeres. Para las mujeres, Alexina era tanto el sujeto sin identidad de un gran deseo como un punto de atracción de su feminidad y para su feminidad, sin que nada las forzase a salir de su mundo enteramente femenino". ${ }^{41}$ Para Alexina la posterior imposición de un verdadero sexo, reclamada por la ley, será una pretensión mezquina que Foucault acabará vinculando a su desgracia y finalmente a su muerte. El derecho, recogiendo las influencias de la ciencia médica, funcionará aquí como una práctica social fundamental a la hora de configurar formas de subjetividad y exigirá entonces una estricta identificación sexual, un sexo verdadero y único, que aclare el estado civil del individuo. Esta identificación sexual va a funcionar en el caso de Alexina como un mecanismo de imposición obligatoria de una identidad que limita y confunde el juego de su sexualidad provocando su infelicidad y su posterior suicidio. Frente a esta imposición jurídica, ese estado anterior cálido y ambiguo en el que vivía Alexina y en el que reinaba una sexualidad indeterminada, es visto por Foucault como un modelo tan apartado de las grises clasificaciones jurídicas como feliz.

Lo fundamental es que el caso de Alexina cuestiona la existencia de un verdadero sexo. ${ }^{42} \mathrm{Su}$ indeterminación anatómica es la base para hacernos dudar primero de la realidad natural de una dicotomía sexual agotadora entre hombres y mujeres, y luego de la sexualidad como la esencia del individuo. Como ha señalado Butler, Herculine no representa una "identidad" sino exactamente lo contrario: la imposibilidad sexual de una identidad. ${ }^{43}$ Se siembra de este modo la duda sobre la conveniencia de una clasificación arbitraria que pretende descubrir y establecer una verdadera sexualidad, aún cuando no está claro (ni entonces ni ahora) cual es el auténtico determinante de su significado: ¿La identidad anatómica, el género, el acto, el orificio, el

\footnotetext{
${ }^{40}$ Idem, pág. 940.

${ }^{41}$ Idem, pág. 940.

42 "Lo que más me ha llamado la atención en el relato de Herculine Barbin es como, en su caso, no existe el verdadero sexo", en: Foucault, M.; “ Il misterioso ermafrodito", en Michel Foucault. Dits et écrits II, 1976-1988, Paris, Gallimard, 2001 (original 1978), p. 624.

${ }^{43}$ Butler, J.; Gender Trouble. Feminism and the Subversion of Identity, London and New York, Routledge, 1999, p. 31.
} 
sentido de las fantasías?. ${ }^{44}$ En este sentido, Foucault considera fundamental escapar de la pretensión de hacernos confesar la verdad sobre nuestro sexo cuya única misión es introducirnos en las definiciones previsibles y arbitrarias de un catálogo en el que ya está todo dicho sobre nosotros.

\section{B. La homosexualidad}

Otra perspectiva privilegiada para hacer estallar la scientia sexualis será, naturalmente, la homosexualidad. Si Foucault elige la homosexualidad como campo para elaborar formas de vida alternativas no es sólo a causa de su experiencia personal, sino porque considera que la homosexualidad tiene algo de indeterminado por su posición oblicua en el mundo de las relaciones sexuales. Precisamente por ello la considera especialmente capaz de propiciar nuevas virtualidades relacionales y afectivas aptas para favorecer nuevas formas de vida.

Pero para lograrlo algunas precauciones han de ser tomadas. En primer lugar hay que evitar hacer caer la homosexualidad en la categoría convencionalmente pensada para ella: Es necesario escapar de las clasificaciones que la colocan en los márgenes de la normalidad de las relaciones sociales. La pretensión de huir de dicha identificación se plantea porque si la homosexualidad va a ser tomada como un punto de partida para la construcción de nuevos estilos de vida, entonces es necesario replantearse su significado para evitar lastrar sus potencialidades con el peso de una categoría ya acuñada. Se trata de vaciar la homosexualidad de su contenido preestablecido para poder utilizarla como el lugar desde el que llevar a cabo una construcción y renovación continua de identidades cambiantes. ${ }^{45}$

De ahí que para Foucault la declaración de la propia homosexualidad tenga un carácter ambiguo, ya que "es una afirmación necesaria puesto que es la afirmación de un derecho, pero al mismo tiempo es la jaula, la trampa". ${ }^{46}$ Es una trampa en cuanto implica caer bajo el control social ejercido sobre el individuo, caer en la imagen del homosexual patologizado como desviado, enfermo o perverso. Por eso, lejos de constituir el final del problema, la declaración de la homosexualidad sólo puede ser tomada como un punto de partida desde el que reconstruir un modo de vida original frente a modelos acuñados.

${ }^{44}$ Butler, J. "Imitación e insubordinación de género", Revista de Occidente, no . 235, 2000, p. 91 .

${ }^{45}$ Halperlin, D.; Saint Foucault. Towards a Gay Hagiography, Oxford, Oxford University Press, 1995, p. 122.

${ }^{46}$ Foucault, M.; "Entretien avec Michel Foucault", en Michel Foucault. Dits et écrits II, 1976-1988, Paris, Gallimard, 2001 (original 1982), p. 1113. 
La declaración es entonces un primer paso para el posterior ejercicio de lo que a Foucault más le interesa y que él mismo denomina prácticas de libertad. ${ }^{47}$ Es importante resaltar aquí que para Foucault una de las claves del problema con el que nos enfrentamos es la pobreza de las relaciones afectivas preexistentes, muy escasas y pensadas en su mayoría para esquemas estrictamente heterosexuales: "Vivimos en un mundo legal, social, institucional donde las únicas relaciones posibles son extremadamente escasas, esquematizadas, pobres." ${ }^{" 48}$ Frente a dicha escasez, la cuestión fundamental es saber cuántas otras formas de relación que hasta ahora no imaginamos pueden existir o ser creadas. El más grave obstáculo al que debemos enfrentarnos a la hora de poner en marcha esas nuevas prácticas de libertad es precisamente la falta de imaginación: lo que el filósofo denomina "la pobreza de nuestro tesoro de imágenes" ${ }^{\text {49 }}$. Este es el lastre que nos impide ver nuevos modelos de relaciones afectivas que enriquezcan la vida de las personas y el panorama social.

Por tanto, la misión es clara: "Deberíamos intentar imaginar y crear un nuevo derecho relacional que permitiera que todos los tipos posibles de relación puedan existir y no sean impedidos, bloqueados o anulados por instituciones relacionalmente empobrecedoras". ${ }^{50} \mathrm{Y}$ para hacerlo la posición de los homosexuales es especialmente privilegiada, dado su carácter oblicuo y ambiguo en el esquema normativo de las relaciones afectivas.

De ahí que el problema no se acabe con declararse homosexual, sino que tal afirmación es útil en cuanto funciona como un punto de partida para ejercer una resistencia constructiva mediante la creación de nuevos modelos de vida. En este sentido el homosexual debe inventar la sexualidad, aprovechando la indeterminación de su estado y su fantasía, y evitando el problemas de la definición de la identidad, sobre todo si se piensa que la identidad homosexual es hoy un dato histórico-cultural estrechamente acuñado. Esa y no otra es la correcta dirección del empeño: "Otra cosa de la que hay que desconfiar es de la tendencia a llevar la cuestión de la homosexualidad al problema del “¿Quién soy? ¿Cuál es el secreto de mi deseo?”.

${ }^{47}$ Foucault, M. 1984. "La ética del cuidado de uno mismo como práctica de libertad", en Hermenéutica del sujeto, Madrid, La Piqueta, 1994 (original 1984), p. 107.

${ }^{48}$ Foucault, M.; "The Social Triumph of the Sexual Will: A Conversation with Michel Foucault", en Michel Foucault. Dits et écrits II, 1976-1988, Paris, Gallimard, 2001 (original 1982), p. 1128.

${ }^{49}$ Foucault, M.; "Sade, sergent du sexe", en Michel Foucault. Dits et écrits I, 1954-1974, Paris, Gallimard, 2001 (original 1975), p. 1689.

${ }^{50}$ Foucault, M.; "The Social Triumph of the Sexual Will: A Conversation with Michel Foucault", en Michel Foucault. Dits et écrits II, 1976-1988, Paris, Gallimard, 2001 (original 1982), p. 1129. 
Quizás sería mejor preguntarse: ¿Qué relaciones se pueden establecer, inventar, multiplicar, modular a través de la homosexualidad?"51

De esta manera, Foucault dará una consistencia específica a lo que denomina ser gay, que interpreta como un paso más allá de la homosexualidad. Ser gay no es simplemente identificarse como homosexual, con el riesgo de encajonarse en una identidad que funciona como una construcción históricocultural demasiado estrecha, sino que significa desarrollar un nuevo modo de vida, para lo que resulta necesario liberarse de los cauces del estereotipo. Se trata de llevar a cabo un esfuerzo productivo que inaugure tipos de comportamiento personal y esquemas relacionales que, articulados incluso en nuevas formas culturales, sean capaces de promover nuevas formas de existencia.

\section{La heterosexualidad}

A partir de ahí el trabajo de formulación de nuevas posibilidades relacionales no será útil sólo para los homosexuales. Foucault sugiere la posibilidad de que esas nuevas formas de vida sean transportables a todas las personas. La huida de una definición normativa de la identidad sexual, el carácter abierto de las prácticas propuestas y la despreocupación por el acto sexual, permitirá que gente no homosexual pueda enriquecer su experiencia a partir de esos nuevos esquemas de relaciones, hasta el punto de que Foucault podrá sostener: "no es necesario ser homosexual para llegar a ser gay." 52

Sin embargo, conviene señalar que Foucault crítica las relaciones heterosexuales sólo desde fuera: es decir, limitándose a poner de manifiesto que sean las únicas relaciones naturales y posibles. Como bien han señalado numerosas pensadoras feministas, Foucault nunca criticó la estructura de dominación subyacente a la relación hombre-mujer que se convierte en el eje de la sexualidad normativa: a saber, la división entre lo masculino y lo femenino. ${ }^{53}$ Por lo tanto, en este punto su trabajo se limita a simples comen-

${ }^{51}$ Foucault, M; «De l'amitié comme mode de vie», en Michel Foucault. Dits et écrits II, 1976-1988, Paris, Gallimard, 2001 (original 1981), pág. 982.

${ }^{52}$ Foucault, M.; "Entretien avec Michel Foucault", en Michel Foucault. Dits et écrits II, 1976-1988, Paris, Gallimard, 2001 (original 1982), p. 1114.

${ }^{53}$ Sandra L. Bartky resume las críticas feministas: "Foucault trata el cuerpo siempre como si se tratase de uno sólo, como si las experiencias corporales de hombres y de mujeres no difiriesen y como si hombres y mujeres soportasen la misma relación con las instituciones características de la vida moderna [...] Las mujeres, como los hombres, están sujetas a algunas de las prácticas disciplinarias que Foucault describe, pero Foucault permanece ciego ante aquellas disciplinas que producen modalidades de subjetivación específicamente femeninas. Pasar por alto las formas de sujeción que engendran el cuerpo femenino es perpetuar el silencio y la impotencia de quienes son sometidas a dichas disciplinas" BARTKY, S. L. "Foucault, Femininity, and the Modernization of Patriarchal Power", en Diamond, I. \& Quinby, L. (eds.); Feminism 
tarios sobre lo que se ha dado en llamar "la crisis de la heterosexualidad." La heterosexualidad contemporánea nace ligada a la revolución industrial, al trabajo asalariado del varón y al papel doméstico de la mujer, cumpliendo una misión productiva y reproductiva. Sin embargo, factores actuales como el paso de una sociedad familiar a una sociedad de individuos, el triunfo de los valores juveniles, el auge del feminismo y su crítica al papel tradicional del varón, los nuevos mecanismos tecnológicos de reproducción de la especie o la crisis de la identidad masculina, hacen que haya llegado a decirse que "en la actualidad, el matrimonio y la pareja estable ya no son el espacio social normativo ni para la reproducción de la especie ni para la expresión de la afectividad y del deseo" 54 y que se anuncie un tránsito de una sexualidad coitocéntrica organizada en torno a la pareja heterosexual hacia nuevas modalidades de expresión. ${ }^{55}$

Nos atrevemos a aventurar aquí que, probablemente, si Foucault no hubiese muerto de forma tan prematura, el tema de la heterosexualidad y la forma en que esta relación ha de ser revolucionada, hubiese sido para él entonces el foco central de su atención.

\section{Los modos de vida}

Como hemos señalado, desprenderse del verdadero sexo es el paso previo a la creación de modos de vida. A pesar de que Foucault no aporta una definición al respecto, podemos considerar que dicha idea se articula en la convergencia de tres líneas fundamentales: la importancia del placer, la despreocupación por el acto sexual y el ejercicio de la ascesis como trabajo de transformación sobre uno mismo.

En primer lugar, por tanto, la creación de nuevas formas de vida está ligada al placer: "Si quisiéramos liberarnos de la ciencia del sexo, se debería encontrar apoyo en el placer, en el máximo del placer." ${ }^{\prime 56}$ Efectivamente, el filósofo francés establece una contraposición entre el deseo como lo específico de la sciencia sexualis y el placer como el posible punto de apoyo para la creación de nuevos modos de vida. El primero es sospechoso, en

and Foucault: Reflections on Resistance, Boston, Northeastern University Press, 1988, pp. 63-64. En definitiva, Foucault no puede escapar de una de las críticas fundamentales que el pensamiento feminista ha dirigido a la tradición filosófica occidental; a saber, que lo que dicha tradición define como "sujeto" es resultado de un "borrado de la diferencia de sexos en los sistemas auto-representativos de un "sujeto masculino", ", en: IrIGARAY, L. Ce sexe qui n'en est pas un, Paris, Les Éditions de Minuit, 1977, p. 72.

${ }^{54}$ Guasch, O.; La crisis de la heterosexualidad, Barcelona, Laertes, 2000, p. 116.

${ }^{55}$ Berger, P. \& Luckmann, T.; La construcción social de la realidad, Buenos Aires, Amorrortu Editores, 1993, pp. 69-70.

${ }^{56}$ Foucault, M.; "Sei to seiji wo Kataru" », en Michel Foucault Dits et écrits II, 19761988, Paris, Gallimard, 2001 (original 1978), pág. 527. 
cuanto ha sido identificado por la Iglesia con el deseo carnal constitutivo del pecado. Además, está cargado de connotaciones médicas y naturalísticas y ha sido utilizado como herramienta para calibrar la normalidad. El segundo es, sin embargo, un término susceptible de alumbrar mayores posibilidades ya que todavía no hay catalogado un placer anormal o un placer patológico. ${ }^{57} \mathrm{El}$ objetivo no será entonces liberar al deseo, "empresa de liberación efectiva [...] que se une a la obra de represión burguesa más general," ${ }^{58}$ sino dejar hablar al placer, visto como el punto de cristalización de una nueva cultura.

Esta pérdida de peso del deseo tiene que ver, en segundo lugar, con la despreocupación por el acto sexual. En la determinación de las nuevas formas de vida se puede apreciar un intento de pasar por encima del orgasmo, del acto sexual elemental, del puro encuentro físico, en beneficio de otras manifestaciones afectivas y relacionales. Foucault critica la sexualidad al uso que ejemplifica Sade (i.e. un programa basado en un sexo anatómico repetitivo y disciplinario, reducido a un recetario de posturas y escenas sexuales que giran en torno al cuerpo y sus órganos) porque el sexo le interesa para pensar a partir de él relaciones afectivas y prácticas sociales que vayan más allá del mero ejercicio de una estrecha sexualidad física. Se trata de hacer de la elección sexual el acicate de un cambio de existencia, transformar la sexualidad en un motor de nuevas formas de vida, convertir el placer en un foco de creación de cultura. El sexo es visto no como una fatalidad sino como una posibilidad de acceder a una vida creadora. Es por eso que el filósofo expresará una prevención respecto al acto sexual que ha llevado a hablar de una desexualización en Foucault, ${ }^{59}$ relacionada con la preocupación por lo que de determinante tiene dicho acto a la hora de configurar al individuo. En definitiva, se trata de escapar de una economía física organizada en función del falo y regida por "leyes que someten lo sexual al poder absoluto de la forma". ${ }^{60}$ Algunos interpretan esta desexualización en relación con el interés por la amistad que Foucault manifestará en sus últimos años. Para otros se refiere a una búsqueda del placer que no gira en torno a una sexualidad reducida a los órganos genitales, sino al conjunto del cuerpo entendido éste como una geografía del placer a la

\footnotetext{
${ }^{57}$ HalPerlin, D.; Saint Foucault. Towards a Gay Hagiography, Oxford, Oxford University Press, 1995, pp. 93-94.

58 Deleuze, G. \& Guattari, F.; El Anti-edipo. Capitalismo y esquizofrenia. Barcelona, Paidós, 1985 (original 1972), p. 54.

${ }^{59}$ ERIBOn, D.; Reflexiones sobre la cuestión gay, Barcelona, Anagrama, 2001, p. 465.

${ }^{60}$ Irigaray, L. Ce sexe qui n'en est pas un, Paris, Les Éditions de Minuit, 1977, p. 109.
} 
manera de Irigaray. ${ }^{61}$ Quizás de lo que se trata es de una desvalorización del acto sexual en aras de una especie de erotización generalizada del mundo al modo de Marcuse. De cualquier manera, la desexualización aparece en Foucault de forma explícita y quizá el mejor ejemplo sea, de nuevo, la homosexualidad.

En este sentido, Foucault constata no sólo que el acto sexual ha dejado de ser un problema entre los homosexuales ("Ahora que los encuentros sexuales han llegado a ser extremadamente fáciles y numerosos, como es el caso de los homosexuales, las complicaciones se producen después"), ${ }^{62}$ sino la escasa preocupación que dicho acto levanta entre los defensores de la sexualidad convencional. En efecto, imaginar un acto sexual no conforme a la naturaleza no es problemático dado que permite catalogar rápida y cómodamente a sus protagonistas como desviados. Lo que realmente inquieta es la trama de relaciones no codificadas que personas del mismo sexo son capaces de establecer. Relaciones extrañas que se escapan a la clasificación, que están fuera de las cerradas taxonomías convencionales y que resultan imprevisibles e incómodas. Y eso es precisamente lo que interesa a Foucault, de la misma manera que le intriga la imagen sugestiva y a la vez misteriosa de dos hombres andando de la mano. Por lo tanto, el problema no es el propio acto (sobre el que en muchas ocasiones se ha obligado a los homosexuales a concentrar todas energías) sino el hecho de que los homosexuales no hayan podido elaborar un sistema relacional original.

En tercer lugar, en esa creación de nuevos modos de vida el individuo ha de realizar un esfuerzo para lograr escapar de rutinas y hábitos. Este esfuerzo es antes que nada un trabajo que el sujeto ha de realizar sobre sí mismo, sobre su forma de pensar y de comportarse. En este sentido, la famosa frase en la que el filósofo afirma que "hay momentos en la vida en que la cuestión de saber si uno puede pensar de un modo diferente al que piensa y percibir de modo distinto de cómo se ve es absolutamente necesaria si uno va a seguir mirando y reflexionando" ${ }^{93}$ introduce un concepto esencial en Foucault que será el de la ascesis. La ascesis entendida no en el sentido convencional de una moral de renuncia, sino precisamente como el trabajo que hace uno sobre sí mismo para transformarse, para acceder a un cierto modo de ser, y especialmente para "hacernos a nosotros mismos infinitamente más suscep-

${ }_{61}$ "De hecho, las zonas erógenas de la mujer no son el clítoris o la vagina, sino el clítoris y la vagina, y los labios, y la vulva, y el cuello uterino, y la matriz, y los senos...lo que hubiera podido, hubiera debido, sorprender es la pluralidad de las zonas erógenas genitales [...] en la sexualidad femenina", en: Idem, pág. 60.

${ }^{62}$ Foucault, M.; "Sexual Choice, Sexual Act", en Michel Foucault. Dits et écrits II, 19761988, Paris, Gallimard, 2001 (original 1982), p. 1150.

${ }^{63}$ Foucault, M.; El uso de los placeres, Madrid, Siglo XXI, 1987 (original 1984), p. 12. 
tibles de placeres". ${ }^{64}$ Este empeño ascético tiene para Foucault un contenido ético. Ético en el sentido antiguo que considera la ética como un trabajo del sujeto sobre sí mismo. Como contraposición a la idea de moralidad entendida como obediencia a un código, idea que Foucault liga a la aparición del cristianismo y que considera en vías de desaparición, de lo que se trata ahora es de remarcar el carácter ético que está implícito en la búsqueda de una forma de existencia personal relacionada con la reconstrucción del yo. ${ }^{65}$ Esta ética del cuidado de sí mismo, abriendo los horizontes personales, es para Foucault una práctica de libertad fundamental.

Una última palabra. Hay que insistir en que inútilmente se buscará en los textos de Foucault una definición de nuevos modos de vida o un catálogo de prácticas o el enunciado de una teoría al respecto. Foucault lo deja claro: “ Tengo cuidado de no imponer mis propios puntos de vista para no cambiar de plan o de programa. [...] No quiero que los homosexuales dejen de creer que es a ellos a quienes les corresponde determinar sus propias relaciones, descubriendo lo que conviene a su situación individual." ${ }^{\prime 66}$ Por tanto, en ningún caso se trata de desalentar la invención de unas prácticas que, por su propia naturaleza, han de ser personalísimas. Más bien, « corresponde a cada persona decidir como tiene que reinventar su vida [...] hay que admitir que hay mil maneras de ser homosexual. La "subjetivación", retomando el término de Foucault, es decir la reinvención de la identidad personal, es un gesto que carece de contenido previo. Al contrario, es a cada uno de nosotros a quien le corresponde darle el sentido que tendrá" 67

$\mathrm{Y}$ es que el objetivo de Foucault no era establecer un recetario de modos de vida. Su misión fundamental era otra. Volviendo al planteamiento inicial de las relaciones entre saber y poder, Foucault ha dejado dicho que un sistema de coacciones se vuelve intolerable cuando los individuos no disponen de los medios para modificarlo. Esto puede ocurrir cuando el sistema se vuelve intocable por considerarlo un imperativo moral o religioso, o por hacer de él la consecuencia de la ciencia médica, o el reflejo de una supuesta naturalidad. Pues bien, con sus excavaciones Foucault ha cumplido con la misión de deshacer la intangibilidad del sistema construido en torno a la sexualidad, al mostrar el carácter contingente de su estrecha catalogación y sus potenciales efectos empobrecedores. Y con ello nos ha colocado en una

\footnotetext{
${ }^{64}$ Foucault, M; «De l'amitié comme mode de vie», en Michel Foucault. Dits et écrits II, 1976-1988, Paris, Gallimard, 2001 (original 1981), p. 984.

${ }^{65}$ HalPerlin, D.; Saint Foucault. Towards a Gay Hagiography, Oxford, Oxford University Press, 1995, p. 68.

${ }^{66}$ Foucault, M.; "Sexual Choice, Sexual Act", en Michel Foucault. Dits et écrits II, 19761988, Paris, Gallimard, 2001 (original 1982), p. 1153.

${ }^{67}$ Eribon, D.; Papiers d'identité. Interventions sur la question gay, Paris, Fayard, p. 80.
} 
nueva posición estratégica en la que se pretende haber ampliado nuestros márgenes de maniobra, a la vez que se nos emplaza al ejercicio de personales y novedosas prácticas de libertad.

\section{Recapitulación}

Por los textos de Foucault caminan los misteriosos hermafroditas, los cálidos internados femeninos, los pederastas, las caricias de los hombres consideradas como arte, los masoquistas, las mujeres que se cogen por el talle, las historias de amor, los hombres que comparten las trincheras, Sade, etc. Personajes, situaciones y espacios que remiten a dos conceptos, "sexo" y "sexualidad", que se han acabado por convertir en palabras-maletas llenas de significados, connotaciones, evocaciones, etc.

Sin embargo, cuando las palabras remiten a tantas cosas se vuelven demasiado difusas y corren el riesgo de vaciarse de significado. Para evitar dicho problema no hay que trabajar en una única definición válida y normativa de cada concepto, sino en una historia del pensamiento que recoja las diferentes definiciones de una idea a lo largo de la historia. En definitiva, un concepto no remite a una unidad, sino a una multiplicidad: es un puzzle formado por tantas piezas como definiciones del mismo se han formulado. Más que buscar una "definición" en el sentido clásico del término, se trata de seguirle a través de sus modificaciones, y eso es lo que intenta Foucault.

En este sentido, a nadie escapa que las miles de páginas dedicadas a la definición de "sexo" y de "sexualidad" nos reenvían a algunos pensadores fundamentales durante el último medio siglo. Sin ninguna duda, al lado de los enfoques psicoanalíticos de Lacan e Irigaray y de la deconstrucción de Derrida, Foucault fue uno de ellos. Su reflexión sobre la sexualidad (reflexión que, como hemos tratado de mostrar, se articula en torno a dos niveles complementarios: una genealogía crítica propuesta en L'Histoire de la sexualité con el objetivo de señalar el carácter histórico y contingente de nuestra sexualidad y un ejercicio filosófico complejo, resumido en la noción de modos de vida y que constituye la propuesta más atrevida de su filosofía) se ha convertido en una referencia fundamental. Por ello, se trataba en este artículo de ofrecer al lector una síntesis que pueda valer como lectura para comprender la influencia de Foucault sobre la sexualidad contemporánea. 